Article

\title{
Filterability of Polysulfone Membrane in a Tilted Panel System for Activated Sludge Filtration
}

\author{
Ahmad Aliyan Alif Ismail ${ }^{1}$, Sri Mulyati ${ }^{2}$ (D) Sri Aprilia ${ }^{2}$, Mohd Hizami Mohd Yusoff ${ }^{1,3}$, \\ Normi Izati Mat Nawi ${ }^{1}$, Muhammad Roil Bilad ${ }^{1,3, * \mathbb{D}}$, Ahmad Fauzi Ismail ${ }^{4}$ \\ and Nasrul Arahman 2,4,5,6,*(D) \\ 1 Department of Chemical Engineering, Universiti Teknologi PETRONAS, Bandar Seri Iskandar, \\ Perak 32610, Malaysia; aliyanalif@gmail.com (A.A.A.I.); hizami.yusoff@utp.edu.my (M.H.M.Y.); \\ normi_16000457@utp.edu.my (N.I.M.N.) \\ 2 Department of Chemical Engineering, Universitas Syiah Kuala, Banda Aceh 23111, Indonesia; \\ sri.mulyati@unsyiah.ac.id (S.M.); sriaprilia@unsyiah.ac.id (S.A.) \\ 3 Department of Chemical Engineering, HICOE-Center of Biofuel and Biochemical Research, \\ Institute of Self-Sustainable Building, Universiti Teknologi PETRONAS, Bandar Seri Iskandar, \\ Perak 32610, Malaysia \\ 4 Advanced Membrane Technology Research Center (AMTEC), School of Chemical and Energy \\ Engineering (SCEE), Universiti Teknologi Malaysia (UTM), Johor 81310, Malaysia; afauzi@utm.my \\ 5 Research Center for Environmental and Natural Resources, Universitas Syiah Kuala, \\ Jl. Hamzah Fansuri, No. 4, Darussalam, Banda Aceh 23111, Indonesia \\ 6 Atsiri Research Center, PUI, Universitas Syiah Kuala, Darussalam, Banda Aceh 23111, Indonesia \\ * Correspondence: mroil.bilad@utp.edu.my (M.R.B.); nasrular@unsyiah.ac.id (N.A.)
}

Received: 15 November 2020; Accepted: 4 December 2020; Published: 16 December 2020

\begin{abstract}
Membrane bioreactors (MBRs) are established technology for treatment of domestic and industrial wastewater because they offer a small footprint and high quality of effluent, in addition to lower excess sludge. However, their widespread applications are still limited by higher expenditure for compensating for membrane fouling. In this study, polysulfone (PSF)-based ultrafiltration membranes were developed and integrated with a tilted panel system for fouling control in activated sludge filtration. The results show an enhanced performance of filtration system thanks to the mutual advantage of the tilted panel system and the membrane properties. Both membranes showed a clear trend of higher permeability with respect to the tilted panel parameters, namely, higher tilting angle, higher aeration rate, and shorter intermittent/switching period. PSF-1 $(1 \mathrm{wt} \%$ polyethylene glycol (PEG) additive) shows significantly better performance than PSF-3 (3 wt $\%$ PEG additive) although their mean flow pore size, structural properties, and contact angle do not differ significantly. PSF-1 shows superior filterability performance of about $45 \%$ for panel tilting angles of $20^{\circ}$ at an aeration rate of $1.8 \mathrm{~L} \cdot \mathrm{min}^{-1}$, and $11 \%$ for a switching period of $1 \mathrm{~min}$ compared with PSF-3. The key property enhancing the performance of the PSF-1 is its narrower distribution of pore size. Overall results suggest that an optimum system could be achieved by optimizing both the filtration system and the membrane material properties.
\end{abstract}

Keywords: membrane fouling control; activated sludge; tilted membrane panel; membrane bioreactor; polysulfone

\section{Introduction}

The membrane bioreactor (MBR) has been established as a promising process to treat activated sludge wastewater because of its interesting properties: it offers a small footprint and high quality of effluent, in addition to lower excess sludge production [1-5]. However, it is subject to membrane 
fouling, which is a major drawback of the process and leads to high operational expenditure $[6,7]$. Despite the maturity of MBRs, a method for efficient control of membrane fouling is still required to enhance their commercialization. Substantial research has been conducted for developing various approaches to improve membrane fouling resistance [8-11]. Membrane fouling controls via physical means (i.e., backwashing, relaxation, air sparging) and chemically via improved chemical cleaning have long been established for improving membrane permeability $[3,9,12-14]$. Such procedures have been incorporated into filtration to allow a more sustained operation. However, opportunities to lower the energy input via other means remain. Most recently, Bilad et al. [15] attempted to reduce membrane fouling via a new approach of using a low-pressure system $(<0.1$ bar $)$, which was applied in this study. The low-pressure system offers sustainable flux, prolonging its operation time and hence requiring less-frequent chemical cleaning.

In addition, the tilted panel concept was introduced as a fouling control method and showed impressive results in reducing the fouling rate [16,17]. This approach was developed with the principle objective of reducing the energy input of air bubbling, which is a common technique for fouling control by improving the contacts between air bubbles and the membrane surface for effective scouring of the foulant layer. However, this system was developed by applying a microfiltration membrane, which often has a high propensity for fouling due to pore blocking. Meanwhile, Osman et al. [18] proposed the use of membrane surface corrugation in a tilted panel system for a membrane bioreactor to improve its energy efficiency. The results reveal that the combination of surface corrugation and panel tilting with relatively higher air bubble rate enhance the permeance up to $47 \%$.

Another common approach for membrane fouling control is modification of the membrane material [19-21]. This is done via exploitation of interfacial interactions of the foulant materials with the membrane surface by imposing hydrophilicity because the base polymer materials for membrane fabrication inherit the hydrophobic nature, which makes them susceptible to fouling [22]. For instance, a simple yet effective vapor-induced phase separation (VIPS) method was suggested by Nawi et al. [23] to improve membrane surface hydrophilicity. In this method, the slow nonsolvent intake helps to prevent excessive leaching of hydrophilic additives due to the formation of an immobile membrane layer on the top of the cast film, which prevents the mobility of the additives during immersion in a coagulation bath.

Extensive reports of using organic and inorganic substances as additives to improve membrane matrix and hydrophilicity have been reported to improve structural properties and to lower hydrophobicity. Mitigation control of fouling has been developed extensively by means of improving the pore size and pore distribution of membranes. These developments mostly involve doping or using a pore-former agent during membrane fabrication with the intention to improve surface hydrophilicity and membrane morphology. Apparently, polyvinylpyrrolidone (PVP) and polyethylene glycol (PEG) as additives have been reported to significantly improve filterability performance due to their hydrophilic nature and ability to act as a good pore former [11,13,19,24-28].

To date, most studies of fouling control have either focused on operational parameters or modifying membrane properties, but few, if any, have focused on optimizing both factors. Therefore, room remains for the optimization of the full potential of membrane filtration by coupling a fouling control system with a suitable membrane. In this study, polysulfone (PSF) membranes with two different PEG concentrations were developed and integrated with a tilted panel system for fouling control in activated sludge filtration. The integrated system was then tested for its filterability performance as a function of tilting parameters (tilting angle, aeration rate, and switching period).

\section{Materials and Methods}

\subsection{Membrane Preparation and Panel Assembly}

Two PSF-based membranes with loading of $1 \mathrm{wt} \%$ and $3 \mathrm{wt} \%$ PEG (20kDa, Sigma-Aldrich, St. Louis, MO, USA) as additive were prepared using the phase inversion method. The PSF concentration 
was fixed at $15 \mathrm{wt}_{\mathrm{t}} \mathrm{o}$. The dope solutions were prepared by solubilizing the PSF and PEG into dimethylacetamide (DMAC, Sigma-Aldrich, St. Louis, MO, USA) as solvent. Membrane samples were coded with respect to PEG loadings (PSF-1 for $1 \mathrm{wt} \%$ PEG, PSF-3 for $3 \mathrm{wt} \%$ PEG). To allow the filtration test, the developed membrane sheets were assembled into two filtration panels, each to a one-sided PVC frame mounting and fixed with two-component epoxy glue (Hardrex, Pahang, Malaysia).

\subsection{Membrane Characterization}

A scanning electron microscope (SEM, ZEISS, Oberkochen, Germany) was used to acquire microscopic images of the developed membranes. The images were used to evaluate the membrane morphology. A capillary flow porometer (CFP, Porolux, Nazareth, Belgium) was used for measuring pore size and pore size distribution. Membrane thickness was measured using an electronic digital micrometer screw gauge (Mitutoyo, Kanagawa, Japan). For determination of static water contact angle (CA), the sessile drop method (Data Physics, Fildestadt, Germany) was used with a water drop size of $3 \mu \mathrm{L}$. Clean water permeability was determined via a filtration test, initially with clean water, immediately prior to running the test with activated sludge feed.

\subsection{Activated Sludge (Feed)}

The activated sludge feed was taken from the local aeration tank of a full-scale wastewater treatment plant. To maintain its condition and to avoid physiological stress of the biomass for prolonged usage, the sludge feed was refreshed daily [29]. The sludge showed $65 \pm 5 \mathrm{mg} / \mathrm{L}$ of chemical oxygen demand, $0.9 \pm 0 \mathrm{mg} / \mathrm{L}$ of total phosphorus, $19 \pm 2 \mathrm{mg} / \mathrm{L}$ of total nitrogen, $4.1 \pm 0.5 \mathrm{~g} / \mathrm{L}$ of mixed liquor suspended solid, and $3.2 \pm 0.3 \mathrm{~g} / \mathrm{L}$ of mixed liquor volatile suspended solid.

\subsection{Filtration Set-Up}

A submerged constant-pressure filtration system with a constant vacuum pressure of 0.1 bar was applied to evaluate the filtration performance of the developed membranes. The filtration tank had a working volume of $5 \mathrm{~L}$ with an air diffuser fixed on the bottom of the tank providing an aeration rate in a range of $0-1.8 \mathrm{~L} / \mathrm{min}$. The permeate was collected during the relaxation period of the filtration. The filtration was performed under a 9.5/0.5 min filtration/relaxation cycle. To maintain liquid volume and feed condition, the permeate was returned to the tank after its volume was measured. Air flowrate was provided using an air pump through a bubble diffuser. The permeate was collected by applying vacuum pressure on the permeate line using a vacuum pump (Gast ${ }^{\mathrm{TM}}$, Benton Harbor, MI, USA) fixed with valves to control and maintain its pressure. The illustration of the experimental set-up is shown in Figure 1.

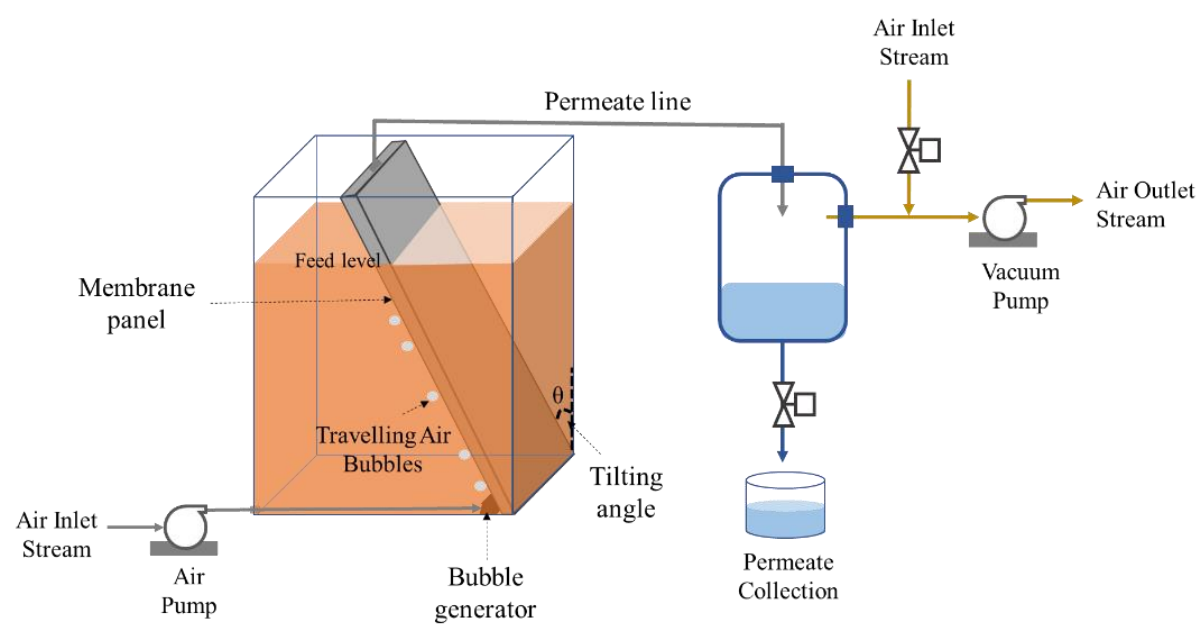

Figure 1. Schematic diagram of the experimental setup of filtration system. 


\subsection{Filterability Test}

The effect of the aeration rate on permeability was investigated at rates of $0,0.36,0.72,1.08,1.44$, and $1.80 \mathrm{~L} \cdot \mathrm{min}^{-1}$ while keeping the tilting angle at $20^{\circ}$ [30]. The tilting angle effect was evaluated at 0 , $5,10,15$, and $20^{\circ}$ while keeping the aeration rate at $1.80 \mathrm{~L} \cdot \mathrm{min}^{-1}$. The switching period was tested at 1.0, 2.5, 5.0, and $7.5 \mathrm{~min}$ while keeping the aeration rate and tilting angle at $1.80 \mathrm{~L} \cdot \mathrm{min}^{-1}$ and $20^{\circ}$ respectively. The filtration tests were conducted for $100 \mathrm{~min}$, when it reached the quasi-steady-state condition. After each filtration, the membrane was cleaned by scrubbing with a sponge and flushing with tap water, after which the panel was soaked in $1 \%$ of sodium hypochlorite (Clorox, Oakland, CA, USA) for one hour to restore the membrane's permeability to $>90 \%$ of its initial value [31].

The measured permeate volume was used to calculate filtration flux (J) and membrane permeability (L) using Equations (1) and (2) respectively.

$$
\begin{aligned}
J & =\frac{V}{A t} \\
L & =\frac{J}{\Delta P}
\end{aligned}
$$

where $\mathrm{V}$ is the permeate volume $(\mathrm{L}), \mathrm{A}$ the total effective filtration area of the membrane $\left(0.012 \mathrm{~m}^{2}\right), \mathrm{t}$ is the total filtration time (h), and $\Delta \mathrm{P}$ is the trans-membrane pressure (bar). The flux and the permeability were calculated by counting the relaxation time within each filtration cycle. The performance of each developed membrane was further investigated by comparing its steady-state permeability values. For each set of experiments, the standard deviation of the last three values were calculated to be represented as error bars in graphs.

\section{Results and Discussion}

\subsection{Membrane Characterization}

Table 1 summarizes the properties of the membranes. Water CA is typically used to evaluate hydrophobicity of the membranes [32] and increasing PEG concentrations results in a slight decrease in the CA values, in which PSF-1 and PSF-3 were 67.9 and $61.8^{\circ}$, respectively. The low CA is due to the properties of PSF, specifically, low surface tension, even without the PEG loadings. Increasing the PEG loading lead to lower CA, probably due to the residual PEG present near the membrane surface. The low CA resulting from PSF-3 can assist in lowering the membrane surface interaction with foulant materials in the activated sludge solution, such as the biomass, exopolymeric particles, protein, and colloids, which are typically hydrophobic.

Table 1. Summary of the membrane properties.

\begin{tabular}{ccccccc}
\hline \multirow{2}{*}{ Code } & $\begin{array}{c}\text { PEG } \\
\text { Loading (\%) }\end{array}$ & $\begin{array}{c}\text { Pore } \\
\text { Morphology }\end{array}$ & $\begin{array}{c}\text { Pore Size } \\
(\mu \mathrm{m})\end{array}$ & $\begin{array}{c}\text { Membrane } \\
\text { Thickness }(\mu \mathrm{m})\end{array}$ & $\begin{array}{c}\text { Contact } \\
\text { Angle }\left({ }^{\circ}\right)\end{array}$ & $\begin{array}{c}\text { Clean Water Permeability } \\
\left(\mathbf{L}^{-} \mathbf{m}^{-\mathbf{2}} \cdot \mathbf{h}^{-\mathbf{1}} \cdot \mathbf{b a r}^{-\mathbf{1}}\right)\end{array}$ \\
\hline PSF-1 & 1 & Asymmetric & 0.04 & $261 \pm 5$ & $67.9 \pm 1.0$ & $923 \pm 54$ \\
PSF-3 & 3 & Asymmetric & 0.03 & $288 \pm 3$ & $61.8 \pm 1.0$ & $817 \pm 35$ \\
\hline
\end{tabular}

SEM images presented in Figure 2 show that both membranes possess a typically asymmetric structure and depict insignificant differences in the surface morphology. However, based on the cross-sectional images, PSF-3 shows a larger finger-like sub-structure compared to PSF-1. This might be due to the mobility of the PEG additive from the membrane matrix to the membrane top layer during immersion in the coagulation bath. However, the formation of a thin top layer on the surface hinders immediate leaching of the additives, which causes additive accumulation near the membrane top surface, thus leading to a polymer-poor phase region. The effect of this phenomena is more prominent for PSF-3 due to its higher additive loading compared to PSF-1. 

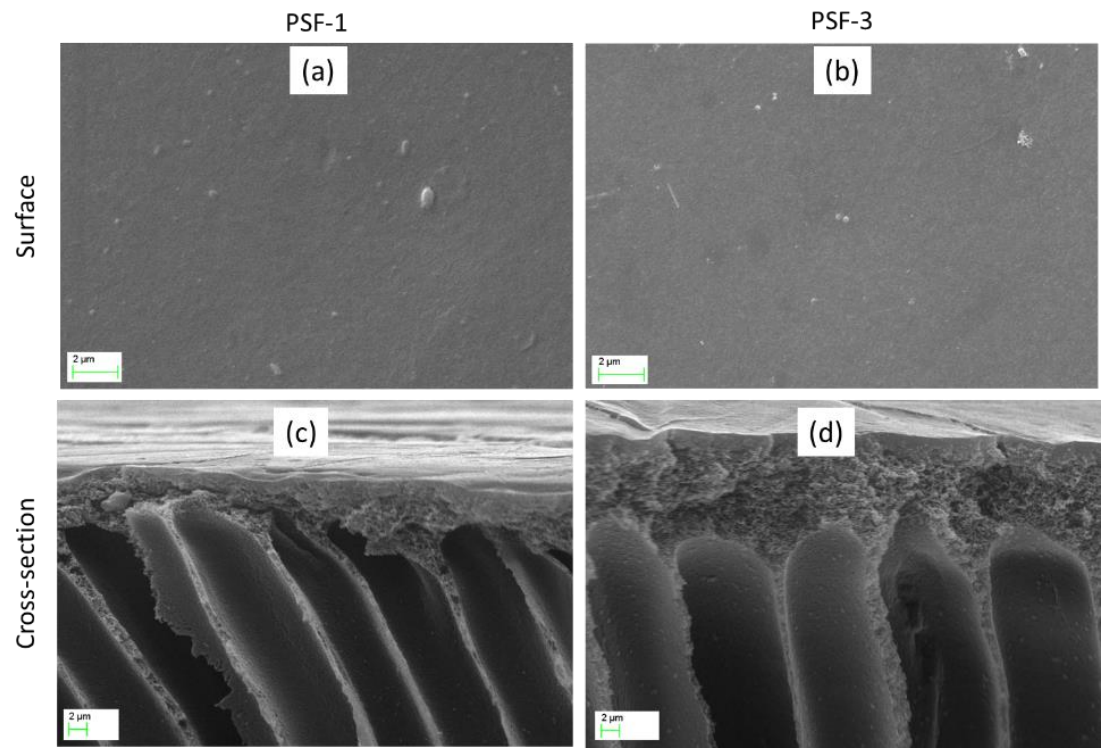

Figure 2. SEM images of the polysulfone (PSF) membranes with different additive (PEG) loading; magnification of $10,000 \times$ for the surface of (a) PSF-1 and (b) PSF-3; magnification of $500 \times$ for the cross-section of (c) PSF-1 and (d) PSF-3.

Notably, PSF-1 has an average pore size of $0.04 \mu \mathrm{m}$, which is slightly larger than that of PSF-3 $(0.03 \mu \mathrm{m})$, as summarized in Table 1 . However, based on the pore size distribution illustrated in Figure 3, PSF-3 has a wider distribution of pore size, ranging from 0.02 to $0.15 \mu \mathrm{m}$, compared to that of PSF-1, ranging from 0.02 to $0.10 \mu \mathrm{m}$. The difference in pore size and pore distribution is mainly due to the role of PEG as a pore-former, which affects the membrane formation [33]. As the PEG loading increased from 1 to $3 \mathrm{wt} \%$, the viscosity of the dope solution increased, leading to a slower demixing, which formed a smaller membrane pore size. The size of flocs in the sludge feed, which ranged from 10 to $70 \mu \mathrm{m}$, was significantly greater than the mean pore size of both membranes, suggesting that both membranes can fully retain the sludge floc in addition to any other free bacteria and microbes. Unfortunately, during prolonged exposure, the ruptured flocs and nutrients may cause irreversible pore blocking.
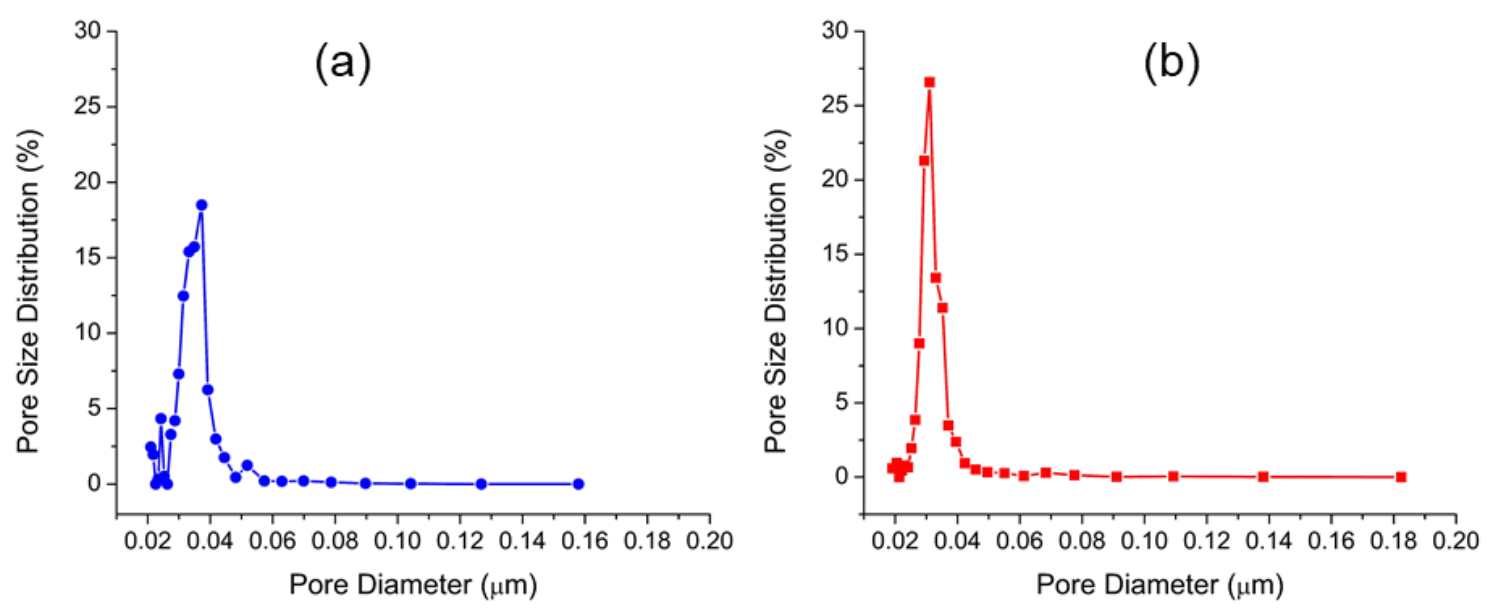

Figure 3. Pore size distribution of PSF-1 (a) and PSF-3 (b).

In this study, the higher mean flow pore size and thinner membrane layer cause by PSF-1 were responsible for its enhanced clean water permeability (Table 1) because these properties reduce the resistance for water transportation across the membrane through the pores. Consequently, the hydraulic 
performance can be significantly improved. Such an intrinsic advantage can be translated into activated sludge filtration performance with appropriate membrane fouling control.

\subsection{Activated Sludge Filtration}

\subsubsection{Effect of Tilting Angle}

Figure 4 demonstrates the effect of panel tilting angle on the membrane filterability performance. Figure 4a depicts the permeability evolution as a function of the filtration time of PSF-1. It was found that all membranes show similar trends in all parametric test studies in this study. The findings show a rapid decline of permeability during the first thirty minutes of the filtration followed by a slower rate of fouling before reaching an approximately steady value. The rapid fouling in the initial stage of the filtration is very common for activated sludge filtration, indicating the occurrence of foulant adsorption, pore blocking, and development of a cake layer. It is also possibly due to ruptured floc fragments, which clog the pore mouths and diminish the flux. A subsequent slower rate of membrane fouling indicates that the system slowly approaches a steady state in which the rate of foulant accumulation is balanced by the rate of back diffusion of foulant from the surface to the bulk to reach an approximately steady state condition [34]. The trend of the permeability as a function of filtration time is identical for all parameters. However, the steady state permeability values are different, which is the true measure of the filtration performance, as illustrated in Figure $4 \mathrm{~b}$.
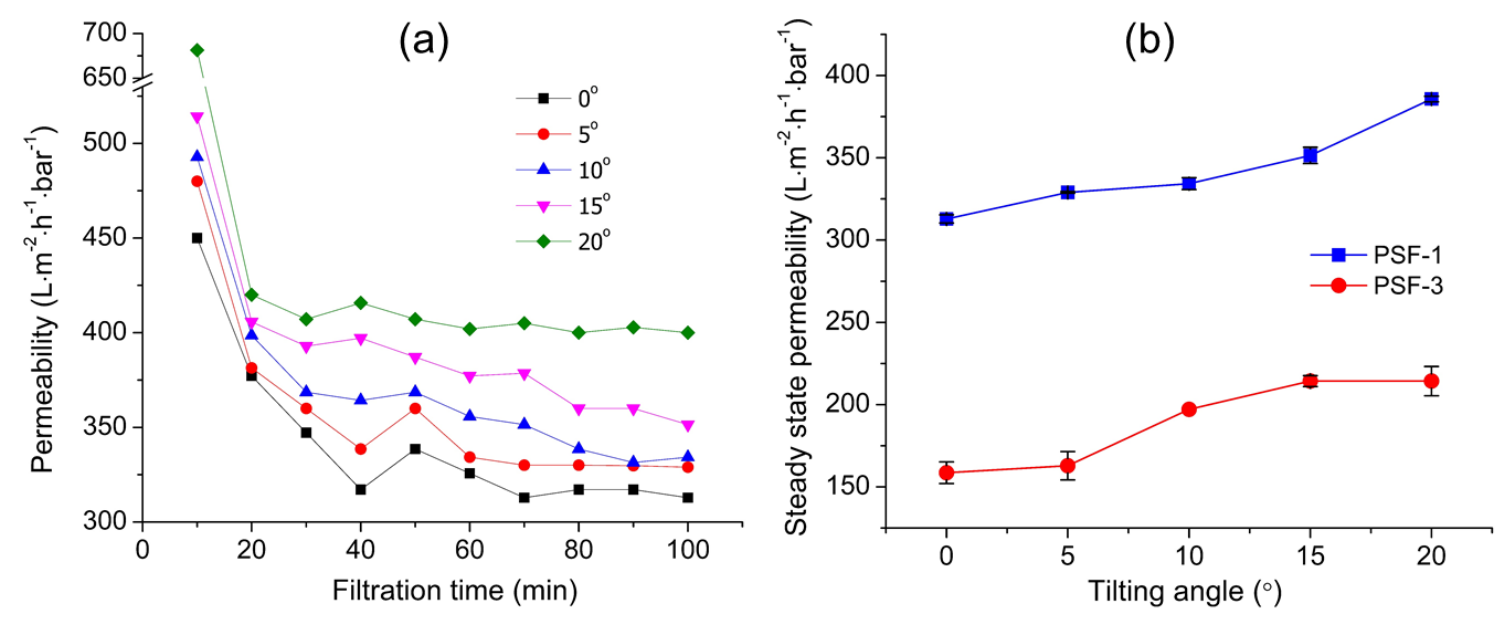

Figure 4. The effects of tilting angle on the permeability performance in terms of filtration time (a) and steady state permeability (b).

Figure $4 \mathrm{~b}$ compares the steady state permeability of PSF- 1 and PSF- 3 as a function of the tilting angle. Overall, both PSF-1 and PSF-3 showed an increase in permeability as the tilting angle is increased, consistent with earlier reports of the same system [15]. At $20^{\circ}$ tilting, the permeability of PSF- 1 and PSF-3 were $390 \mathrm{~L} \cdot \mathrm{m}^{-2} \cdot \mathrm{h}^{-1} \cdot \mathrm{bar}^{-1}$ and $215 \mathrm{~L} \cdot \mathrm{m}^{-2} \cdot \mathrm{h}^{-1} \cdot \mathrm{bar}^{-1}$, respectively, representing an increase of about $20 \%$ compared to the vertical configurations (tilting angle of $0^{\circ}$ ). The higher steady state permeability shown by PSF-1 suggests that a membrane with larger pore size, greater hydrophilic surface, and lower film thickness is favorable for this system for enhanced filterability performance and antifouling properties. Tilting the panel optimizes the flow-path trajectory of the air bubbles by increasing the contacts and thus imposing greater shear rates between the bubbles and the membrane's surface. As a result, the bubble scouring effect is more effective for removing the foulant [16]. Increasing the tilting angle further $\left(>20^{\circ}\right)$ likely increases the scouring performance for PSF-1 but seems to offer minimal improvement for PSF-3. However, tilting angles greater than $20^{\circ}$ could not be applied due to technical restrictions. Higher tilting angles have drawbacks, including that the panel needs more space to operate, thus increasing the footprint of the system. 


\subsubsection{Effect of Aeration Rate}

The effect of the aeration rate was evaluated by comparing the steady state permeability at different air flow rates (Figure 5). Overall, both PSF-1 and PSF-3 showed a steady increase in permeability with an increment in aeration rate, which is consistent with other findings $[16,35,36]$. An aeration rate of $1.8 \mathrm{~L} \cdot \mathrm{min}^{-1}$ improves water permeability by $\pm 10 \%$ compared to the non-aerated system. Increasing the aeration rate imposes greater shear rates between the bubbles and the membrane's surface, creating a more vigorous bulk fluid movement, and providing more mass and momentum transfer to scour the foulants [30].

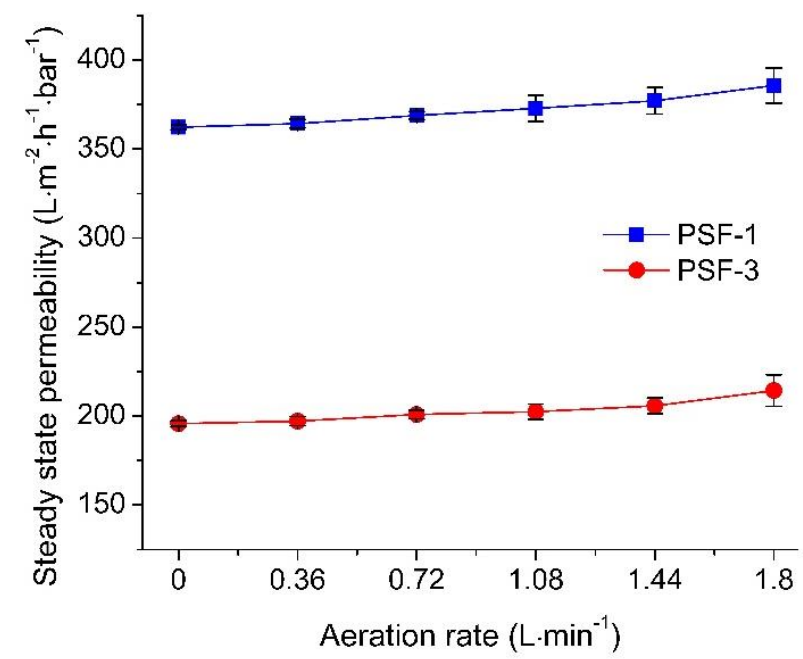

Figure 5. The effects of aeration rate on the steady state permeability of PSF membranes with different composition.

Comparison between the results in Figures $4 \mathrm{~b}$ and 5 shows that the aeration rate has a less prominent impact than the tilting angle in enhancing steady state permeability. This finding indicates that the intensity of air bubble contacts, which is dictated by panel tilting, is more important than the number of air bubbles, which is dictated by the aeration rate. Moreover, an increase in air flowrate increases the air compressor duty, thus increasing energy consumption and leading to an increase in operating cost. The combined effect of aeration rate and tilting angle can be used as a basis of optimization to maximize the throughput while also minimizing energy consumption [37].

\subsubsection{Effect of Switching Period/Intermittent Aeration}

This study reveals that a shorter switching period generally achieved higher steady state permeability. The switching period in this case can be seen in two ways: (1) operation of a two-sided membrane or (2) operation of a one-sided membrane with intermittent aeration. The former is a system that involves switching the panel periodically so that both sides of the panel are intermittently exposed to aeration. This first approach offers a higher throughput due to higher module packing density but results in operation complexity due to the need to switch the panel. The second approach offers a $50 \%$ reduction in aeration energy, reflected in lower cost of module packing density and higher membrane cost, because the panel is mounted by the membrane on only one side (tilted toward the aeration). Selection of the two approaches must consider both capital and operational expenditure, and will be examined in a separate future study.

Figure 6 shows that $1 \mathrm{~min}$ switching on PSF-1 resulted in permeability of $398 \mathrm{~L} \cdot \mathrm{m}^{-2} \cdot \mathrm{h}^{-1} \cdot \mathrm{bar}^{-1}$, which is $25 \%$ higher than that of $10 \mathrm{~min}$ switching $\left(297 \mathrm{~L} \cdot \mathrm{m}^{-2} \cdot \mathrm{h}^{-1} \cdot \mathrm{bar}^{-1}\right)$, although the system was run under a similar aeration rate. Upon switching, the membrane surface is exposed to irreversible fouling without the aid of aeration to control fouling. This results in more severe fouling (i.e., pore blocking) during a long intermittent aeration period, which reduces the permeability, consistent with earlier 
reports [16,21,34]. During a short period of intermittent aeration, the permeability can be maintained because of the short period of foulant accumulation when there is no aeration. As the switching period is prolonged, the period for foulant accumulation is also longer, which leads to formation of a more compact cake layer that cannot be removed during the aeration period.

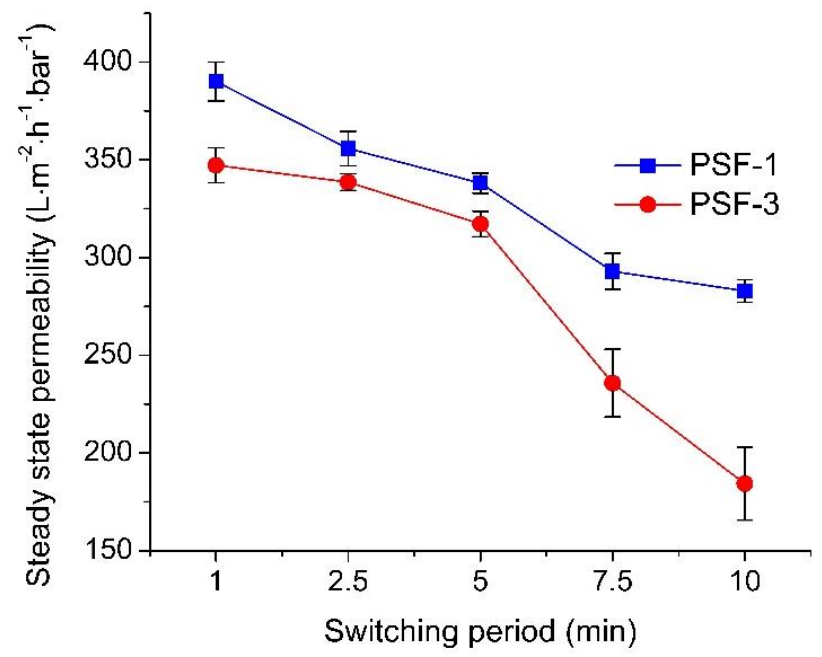

Figure 6. The effects of switching period on the steady-state permeability.

Significant aeration energy can be achieved by applying intermittent aeration in a tilted panel or under switching. For all filterability tests reported in Figure 6, the aeration energy could be reduced by $50 \%$ without sacrificing the filtration performance. Under the tilted panel system, the three parameters of tilting angle, aeration rate, and switching period/intermittent aeration can be optimized to achieve the specific energy input. The effect of membrane properties is another factor discussed in Section 3.3.

\subsection{Effect of Membrane Properties}

The findings in Section 3.2 demonstrate the superiority of the PSF-1 membrane compared to the PSF-3 membrane under all ranges of the tested parameters. The steady state permeability of PSF-1 is almost double that of PFS-3 for the test on the effect of tilting angle. Moreover, despite showing a similar trend of increase in steady state permeability at a higher tilting angle, the impact of tilting angle is more prominent for PSF-1. Increasing the tilting angle from 0 (vertical) to $20^{\circ}$ enhances the steady state permeability by $\pm 73 \mathrm{~L} \cdot \mathrm{m}^{-2} \cdot \mathrm{h}^{-1} \cdot \mathrm{bar}^{-1}$ for PSF-1 and only $56 \mathrm{~L} \cdot \mathrm{m}^{-2} \cdot \mathrm{h}^{-1} \cdot \mathrm{bar}^{-1}$ for PSF-3. PSF-1 has greater pore size and clean water permeability compared to PSF-3, although it is slightly more hydrophobic than PSF-3 (i.e., CA for PSF-1 is $6.1^{\circ}$ higher than that of PSF-3). Increasing the concentration of the PEG additives does not provide the hydraulic advantage. The advantage of PSF-1 can be ascribed to its higher intrinsic properties (shown by higher permeability) and its narrower pore size distribution. Some fraction of large pore sizes $(>0.1 \mu \mathrm{m})$ in PSF-3 appear more vulnerable to pore blocking of activated sludge fragments (such as exopolymeric particles). Such pore blockage severely decreases the permeate flux and diminishes the hydraulic performance.

PSF-1 also shows better permeability performance than PSF-3 with a difference of $\pm 100 \mathrm{~L} \cdot \mathrm{m}^{-2} \cdot \mathrm{h}^{-1} \cdot \mathrm{bar}^{-1}$ for the test on the effect of aeration rate. Although PSF-3 has higher hydrophilicity because it has a lower contact angle compared to PSF-1 and is theoretically less prone to severe fouling [7], the effect of hydrophilicity on the development of membrane fouling was less significant compared to the effect of pore blocking. Pore blocking mostly occurs during the initial stage of filtration when the convective flow of the liquid drags the foulant toward the membrane surface to initiate blockage of the pore mouth.

The advantage of PSF-1 over PSF-3 was also consistent during the intermittent aeration tests. Steady state permeability of PSF-1 was 39\% higher than that of PSF-3 and the effect was more significant 
for longer intermittent periods. The finding indicates a severe effect of pore blocking during a long idle period (without aeration) and the foulant could not be effectively removed during the aeration period, as also reported in previous research [37].

The distinct performances of the two membrane samples examined in this study suggest the importance of careful screening of a membrane material for a particular filtration system. PSF-1 offers significant advantages compared to PSF-3 due to its narrower pore size distribution. A small fraction of pores with large size contributed significantly to lowering the overall hydraulic performance. Table 2 summarizes several studies of treating activated sludge by applying MBRs with various system configurations and membrane properties. This proves that the outcomes of this study are comparable with other systems proposed in previous research.

Table 2. Performance of PSF membranes with variable properties applied in membrane bioreactor (MBR) systems to treat activated sludge using different system configurations.

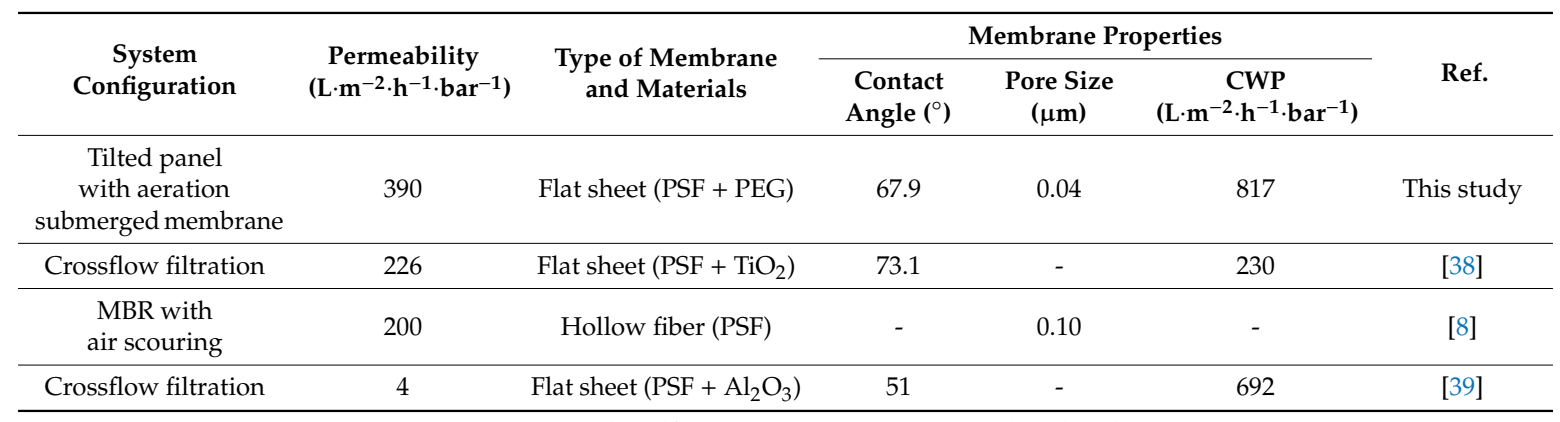

CWP, clean water permeability; PSF, polysulfone; PEG, polyethylene glycol; $\mathrm{Al}_{2} \mathrm{O}_{3}$, aluminum oxide; $\mathrm{TiO}_{2}$, titanium dioxide.

\section{Conclusions}

This study showed enhanced performance of a filtration system via the mutual advantages of a module system and a membrane material as an effective membrane fouling control strategy for activated sludge filtration. Both membrane samples showed consistent trends when tested under different parameters in the tilted panel system, demonstrating better performance with higher tilting angle, higher aeration rate, and shorter intermittent/switching period. However, PSF-1 showed significantly better performance than PSF-3. The mean flow pore size, structural properties, and CA of both membranes did not differ significantly. The key property dictating the superior performance of PSF-1 is its narrow pore size distribution. To achieve maximum throughput and minimum energy input, the overall results demonstrate the importance of optimizing both module system and membrane material properties.

Author Contributions: Writing —original draft preparation, investigation, A.A.A.I.; supervision, manuscript revision, M.H.M.Y.; visualization, writing - review and editing, N.I.M.N.; conceptualization, methodology, validation, supervision, N.A. and M.R.B.; funding acquisition, writing - review and editing, S.M., S.A. and A.F.I. All authors have read and agreed to the published version of the manuscript.

Funding: This research received no external funding.

Acknowledgments: Acknowledgment to Universitas Syiah Kuala, Universiti Teknologi Malaysia, and Universiti Teknologi Petronas for supporting research collaboration. Thanks to the directorate general of higher education, Indonesia's ministry of education and culture for their financial contribution through the world-class professor program (2020).

Conflicts of Interest: The authors declare no conflict of interest.

\section{References}

1. Mutamim, N.S.A.; Noor, Z.Z.; Hassan, M.A.A.; Olsson, G. Application of membrane bioreactor technology in treating high strength industrial wastewater: A performance review. Desalination 2012, 305, 1-11. [CrossRef]

2. Gunatilake, S. Methods of removing heavy metals from industrial wastewater. Methods 2015, 1, 14. 
3. Aslam, M.; Charfi, A.; Lesage, G.; Heran, M.; Kim, J. Membrane bioreactors for wastewater treatment: A review of mechanical cleaning by scouring agents to control membrane fouling. Chem. Eng. J. 2017, 307, 897-913. [CrossRef]

4. Iorhemen, O.T.; Hamza, R.A.; Tay, J.H. Membrane bioreactor (MBR) technology for wastewater treatment and reclamation: Membrane fouling. Membranes 2016, 6, 33. [CrossRef] [PubMed]

5. Xiao, K.; Xu, Y.; Liang, S.; Lei, T.; Sun, J.; Wen, X.; Zhang, H.; Chen, C.; Huang, X. Engineering application of membrane bioreactor for wastewater treatment in China: Current state and future prospect. Front. Environ. Sci. Eng. 2014, 8, 805-819. [CrossRef]

6. Defrance, L.; Jaffrin, M.Y.; Gupta, B.; Paullier, P.; Geaugey, V. Contribution of various constituents of activated sludge to membrane bioreactor fouling. Bioresour. Technol. 2000, 73, 105-112. [CrossRef]

7. van der Marel, P.; Zwijnenburg, A.; Kemperman, A.; Wessling, M.; Temmink, H.; van der Meer, W. Influence of membrane properties on fouling in submerged membrane bioreactors. J. Membr. Sci. 2010, 348, 66-74. [CrossRef]

8. Hong, S.; Bae, T.-H.; Tak, T.; Hong, S.; Randall, A. Fouling control in activated sludge submerged hollow fiber membrane bioreactors. Desalination 2002, 143, 219-228. [CrossRef]

9. Hwang, T.; Oh, Y.-K.; Kim, B.; Han, J.-I. Dramatic improvement of membrane performance for microalgae harvesting with a simple bubble-generator plate. Bioresour. Technol. 2015, 186, 343-347. [CrossRef]

10. Juang, R.-S.; Chen, H.-L.; Chen, Y.-S. Membrane fouling and resistance analysis in dead-end ultrafiltration of Bacillus subtilis fermentation broths. Sep. Purif. Technol. 2008, 63, 531-538. [CrossRef]

11. Kim, J.-H.; Lee, K.-H. Effect of PEG additive on membrane formation by phase inversion. J. Membr. Sci. 1998, 138, 153-163. [CrossRef]

12. Arefi-Oskoui, S.; Khataee, A.; Safarpour, M.; Orooji, Y.; Vatanpour, V. A review on the applications of ultrasonic technology in membrane bioreactors. Ultrason. Sonochem. 2019, 58, 104633. [CrossRef]

13. Gebru, K.A.; Das, C. Effects of solubility parameter differences among PEG, PVP and CA on the preparation of ultrafiltration membranes: Impacts of solvents and additives on morphology, permeability and fouling performances. Chin. J. Chem. Eng. 2017, 25, 911-923. [CrossRef]

14. Naddeo, V.; Borea, L.; Belgiorno, V. Sonochemical control of fouling formation in membrane ultrafiltration of wastewater: Effect of ultrasonic frequency. J. Water Process. Eng. 2015, 8, e92-e97. [CrossRef]

15. Bilad, M.R.; Nawi, N.I.M.; Subramaniam, D.D.; Shamsuddin, N.; Khan, A.L.; Jaafar, J.; Nandiyanto, A.B.D. Low-pressure submerged membrane filtration for potential reuse of detergent and water from laundry wastewater. J. Water Process. Eng. 2020, 36, 101264. [CrossRef]

16. Eliseus, A.; Bilad, M.R.; Nordin, N.A.H.M.; Khan, A.L.; Putra, Z.A.; Wirzal, M.D.H.; Aslam, M.; Aqsha, A.; Jaafar, J. Two-way switch: Maximizing productivity of tilted panel in membrane bioreactor. J. Environ. Manag. 2018, 228, 529-537. [CrossRef] [PubMed]

17. Eliseus, A.; Bilad, M.; Nordin, N.; Putra, Z.; Wirzal, M. Tilted membrane panel: A new module concept to maximize the impact of air bubbles for membrane fouling control in microalgae harvesting. Bioresour. Technol. 2017, 241, 661-668. [CrossRef]

18. Osman, A.; Nawi, M.; Izati, N.; Samsuri, S.; Bilad, M.R.; Shamsuddin, N.; Khan, A.L.; Jaafar, J.; Nordin, N.A.H. Patterned Membrane in an Energy-Efficient Tilted Panel Filtration System for Fouling Control in Activated Sludge Filtration. Polymers 2020, 12, 432. [CrossRef]

19. Idris, A.; Zain, N.M.; Noordin, M. Synthesis, characterization and performance of asymmetric polyethersulfone (PES) ultrafiltration membranes with polyethylene glycol of different molecular weights as additives. Desalination 2007, 207, 324-339. [CrossRef]

20. Jeon, S.; Rajabzadeh, S.; Okamura, R.; Ishigami, T.; Hasegawa, S.; Kato, N.; Matsuyama, H. The effect of membrane material and surface pore size on the fouling properties of submerged membranes. Water 2016, 8, 602. [CrossRef]

21. Li, F.; Meng, J.; Ye, J.; Yang, B.; Tian, Q.; Deng, C. Surface modification of PES ultrafiltration membrane by polydopamine coating and poly (ethylene glycol) grafting: Morphology, stability, and anti-fouling. Desalination 2014, 344, 422-430. [CrossRef]

22. Fang, H.H.; Shi, X. Pore fouling of microfiltration membranes by activated sludge. J. Membr. Sci. 2005, 264, 161-166. [CrossRef] 
23. Mat Nawi, N.I.; Chean, H.M.; Shamsuddin, N.; Bilad, M.R.; Narkkun, T.; Faungnawakij, K.; Khan, A.L. Development of Hydrophilic PVDF Membrane Using Vapour Induced Phase Separation Method for Produced Water Treatment. Membranes 2020, 10, 121. [CrossRef] [PubMed]

24. Garcia-Ivars, J.; Alcaina-Miranda, M.-I.; Iborra-Clar, M.-I.; Mendoza-Roca, J.-A.; Pastor-Alcañiz, L. Enhancement in hydrophilicity of different polymer phase-inversion ultrafiltration membranes by introducing PEG/Al2O3 nanoparticles. Sep. Purif. Technol. 2014, 128, 45-57. [CrossRef]

25. Sinha, M.; Purkait, M. Increase in hydrophilicity of polysulfone membrane using polyethylene glycol methyl ether. J. Membr. Sci. 2013, 437, 7-16. [CrossRef]

26. Su, Y.-L.; Cheng, W.; Li, C.; Jiang, Z. Preparation of antifouling ultrafiltration membranes with poly (ethylene glycol)-graft-polyacrylonitrile copolymers. J. Membr. Sci. 2009, 329, 246-252. [CrossRef]

27. Xu, Z.L.; Qusay, F.A. Effect of polyethylene glycol molecular weights and concentrations on polyethersulfone hollow fiber ultrafiltration membranes. J. Appl. Polym. Sci. 2004, 91, 3398-3407. [CrossRef]

28. Yunos, M.Z.; Harun, Z.; Basri, H.; Ismail, A.F. Studies on fouling by natural organic matter (NOM) on polysulfone membranes: Effect of polyethylene glycol (PEG). Desalination 2014, 333, 36-44. [CrossRef]

29. Ioan, C.; Robescu, D.N. Effect of increased inflow and dilution on the activated sludge properties and viability of microbial community. UPB Sci. Bull 2015, 77, 197-204.

30. Eliseus, A.; Putra, Z.; Bilad, M.; Nordin, N.; Wirzal, M.; Jaafar, J.; Khan, A.L. Energy minimization of a tilted panel filtration system for microalgae filtration: Performance modeling and optimization. Algal Res. 2018, 34, 104-115. [CrossRef]

31. Ujihara, R.; Mino, Y.; Takahashi, T.; Shimizu, Y.; Matsuyama, H. Effects of the ionic strength of sodium hypochlorite solution on membrane cleaning. J. Membr. Sci. 2016, 514, 566-573. [CrossRef]

32. Subedi, D. Contact angle measurement for the surface characterization of solids. Himal. Phys. 2011, 2, 1-4. [CrossRef]

33. Ma, Y.; Shi, F.; Ma, J.; Wu, M.; Zhang, J.; Gao, C. Effect of PEG additive on the morphology and performance of polysulfone ultrafiltration membranes. Desalination 2011, 272, 51-58. [CrossRef]

34. Lau, A.K.; Bilad, M.; Nordin, N.; Faungnawakij, K.; Narkkun, T.; Wang, D.K.; Mahlia, T.; Jaafar, J. Effect of membrane properties on tilted panel performance of microalgae biomass filtration for biofuel feedstock. Renew. Sustain. Energy Rev. 2020, 120, 109666. [CrossRef]

35. Nawi, M.; Izati, N.; Abd Halim, N.S.; Lee, L.C.; Wirzal, M.D.H.; Bilad, M.R.; Nordin, N.A.H.; Putra, Z.A. Improved Nylon 6, 6 Nanofiber Membrane in A Tilted Panel Filtration System for Fouling Control in Microalgae Harvesting. Polymers 2020, 12, 252. [CrossRef]

36. Razak, N.N.A.N.; Rahmawati, R.; Bilad, M.R.; Pratiwi, A.E.; Elma, M.; Nawi, N.I.M.; Jaafar, J.; Lam, M.K. Finned spacer for enhancing the impact of air bubbles for membrane fouling control in Chlorella vulgaris filtration. Bioresour. Technol. Rep. 2020, 11, 100429. [CrossRef]

37. Miyoshi, T.; Yuasa, K.; Ishigami, T.; Rajabzadeh, S.; Kamio, E.; Ohmukai, Y.; Saeki, D.; Ni, J.; Matsuyama, H. Effect of membrane polymeric materials on relationship between surface pore size and membrane fouling in membrane bioreactors. Appl. Surf. Sci. 2015, 330, 351-357. [CrossRef]

38. Bae, T.-H.; Tak, T.-M. Effect of TiO2 nanoparticles on fouling mitigation of ultrafiltration membranes for activated sludge filtration. J. Membr. Sci. 2005, 249, 1-8. [CrossRef]

39. Homayoonfal, M.; Mehrnia, M.R.; Rahmani, S.; Mojtahedi, Y.M. Fabrication of alumina/polysulfone nanocomposite membranes with biofouling mitigation approach in membrane bioreactors. J. Ind. Eng. Chem. 2015, 22, 357-367. [CrossRef]

Publisher's Note: MDPI stays neutral with regard to jurisdictional claims in published maps and institutional affiliations.

(C) 2020 by the authors. Licensee MDPI, Basel, Switzerland. This article is an open access article distributed under the terms and conditions of the Creative Commons Attribution (CC BY) license (http://creativecommons.org/licenses/by/4.0/). 